\title{
Phytochemical Screening and Identification of Bioactive Constituents of the Chloroform Extract of Icacina Trichantha Tuber Peel Oliv
}

\author{
*AKOH, OU; MAC-KALUNTA, OM \\ Department of Chemistry, Michael Okpara University of Agriculture Umudike, P.M.B. 7267, Umuahia, Abia state, Nigeria \\ *Corresponding Author Email: onyilac@gmail.com
}

\begin{abstract}
This study was carried out to identify the bioactive constituents of the tuber peels of Icacina trichanthalinna of theIcacinales family. This plant is basically selected due to its widespread use in herbal treatment. Nine compounds were identified in the chloroform extract of the tuber peel. Undecane (43.254\%),2 hexanone(23.299\%),Dodecanoic acid ethyl ester(6.244\%) and 9-octadecynoic acid(5.915\%) appeared to be the most prevailing compounds and they are known to possess antibacterial, antiviral, antioxidant, antimycobacterial, hypercholesterolemic activities. Also identified was triarachine which has been reported to have some biological activity.
\end{abstract}

\section{DOI: https://dx.doi.org/10.4314/jasem.v25i7.3}

Copyright: Copyright (C) 2021 Akoh and Mac-Kalunta. This is an open access article distributed under the Creative Commons Attribution License (CCL), which permits unrestricted use, distribution, and reproduction in any medium, provided the original work is properly cited.

Dates: Received: 10 May 2021; Revised: 28 June 2021; Accepted: 01 July 2021

Keywords: Medicinal plants, Icacinatrichantha, chloroform extract, GC-MS, Analysis.

Medicinal based plants also called medicinal herbsare of great use today, particularly in the developing countries of the world. This is because they are very available, cheap, and safe. Medicinal plants have been used in traditional medicine practices since prehistoric times. Plants synthesize hundreds of chemical compounds for functions including defense against insect, fungi, diseases, and herbivorous mammals. Folkloric stories and ideas have always played an important role in creating of novel bioactive components for therapeutic purposes (Awa et al., 2012). Drug research makes use of ethno botany to search for pharmacologically active substance in nature, and has in this way discovered hundreds of useful compounds. Medicinal plants have been known to have a very high efficacy and that is why most people (about 78\%) of the people in the rural communities rely on them for effective method for their primary health care because of the presence diverse bioactive components present in them, which have some pharmacological activities and nutritional values in the body of living organisms (Burkhill, 1985). Icacina hantha belongs to the family of Icacinales. Other species of this plants includes Icacinatric laessensii De wild, Icacinaguess feldtii Asch, Icacina mannii oliv, Icacina oliviformis (poir), Icacinatric hantha oliv.

Icacinatric hantha Oliv. (Icacinaceae) is a perennial shrub up to $2 \mathrm{~m}$ with scan dent growth above. It is commonly found in field crops, forest re-growths and waste areas in most part of Nigeria (Burkhill, 1994; Della Loggia, 1999). Icacinaceae comprises over 8 species including Icacinatrichantha as one of the genera in the family. Icacina trichantha oliv.is popularly referred to as Gbegbe in Yoruba western Nigeria (meaning carry away) while Igbos in the eastern part of Nigeria calls it Ibugo (Edorios and Ekpete, 2015).It thrives better in colonies. The plant is reported to become a weed of rice-padis in former Bendel State presently Edo and Delta States in Nigeria. The peel has been used extensively by herbalists and traditional doctors in the treatment of poisoning, constipation, to induce emesis and to cure malaria.It is used infolks medicine as antiinflammatory, anti-convulsion, anti-diabetic and antimalarial in different part of African (Holldobler, 1990). Some already isolated compounds from different parts of this plant has been reported to possess anti-inflammatory, anti-diabetic, antimicrobial, anti-oxidant, anti-gene toxic, anti-cytotoxic and hepatoprotective activity (Ezeigbo, 2010). Pytochemical examination of Icacina trichantha peels indicated the presence of alkaloids, phenols, tannins, flavonoids, saponins, steroids, terpenoids and glycosides (Shagal et al., 2014). The leaves and seeds, when crushed and macerated in local gin, can be used for the treatment of hypertension and asthma (Ajibensin et al., 2008). Tubers are used by traditional healers to treat various medical conditions including constipation, poisoning, malaria, rheumatism, toothache, as well as to induce emesis and abortion. 
The tuber juice can be used for treating mumps (Ubom, 2010). This study is geared at identifying the bioactive constituents in the chloroform extract of icacina trichantha tuber peel oliv as well as the phytochemical study.

\section{MATERIALS AND METHODS}

Sample Collection: The Plant (sample) was harvested at Umunakukwu Chokoneze Mbaise, Imo State in August 2019 and identified in Forestry Department of Michael Okpara University of Agriculture, Umudike, Abia State, Nigeria and given a herbarium number ICA DALZ. 1094.

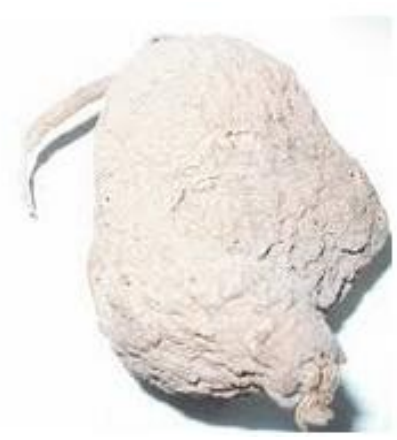

Fig 1. Icacinatri chantha tuber

Preparation and Extraction: The tuber was well washed in running water to remove sands and unwanted debris, rinsed with sterile distilled water and then peeled. The tuber peel was air dried for four weeks, crushed into pieces with mortar and pistol and weighed. The weight was found to be $500 \mathrm{~g}$. The pulverized peel was keptin a clean tight waterproof till use. It was extracted using $1500 \mathrm{ml}$ of chloroform for 48 hours. The extracts were then filtered using Whatman filter paper. The filtrate was concentrated using rotary evaporator. $2 \mathrm{~g}$ of the chloroform extract was used for GC-MS because of the clearer separation from the TLC done.

Phytochemical Screening: The phytochemical screening of the plant extract was qualitatively analyzed in details using a standard protocol.

Test for alkaloids: 1gof the chloroform extract was dissolved in $5 \mathrm{ml}$ of $10 \%$ ammonia solution and the extracted with $15 \mathrm{ml}$ of chloroform. The portion was evaporated to dryness and the resultant residue dissolved in $15 \mathrm{ml}$ dilute sulphuric acid.

Meyer reagent test: drops of the reagent was added to a portion of the acidic solution in test tube and observed for a yellowish precipitate indicative of the presence of alkaloids.
Test for steroid: $2 \mathrm{ml}$ of chloroform and concentrated $\mathrm{H}_{2} \mathrm{SO}_{4}$ were added with $5 \mathrm{ml}$ of aqueous plant crude extract. In lower chloroform layer, red colour appeared indicating the presence of steroids. Another test was performed by mixing crude extract with $2 \mathrm{ml}$ of chloroform. Then $2 \mathrm{ml}$ of each of concentrated $\mathrm{H}_{2} \mathrm{SO}_{4}$ and acetic were poured into the mixture. The greenish coloration indicated the presence of steroids.

Test for glycosides: $2 \mathrm{ml}$ of glacial acetic acid was used to treat the extract, then 1 droplet of $\mathrm{FeCl}_{3}$ was added and concentrated $\mathrm{H}_{2} \mathrm{SO}_{4}$ of $1 \mathrm{ml}$. the presence of brown colouration showed the presence of glycoside.

Test for saponins: $20 \mathrm{ml}$ of distilled water was mixed with aqueous crude extract in a test tube and it was shaken by hand for 15 minutes. Foam later was obtained on the top of the test tube. The Frothing was mixed vigorously with few drops of olive and it persisted. This foam layer indicates the presence of saponins.

Test for tannin: $2 \mathrm{~g}$ of the chloroform extract was boiled with $5 \mathrm{ml}$ of $45 \%$ ethanol. The mixture was allowed to cool, therefore it was filtered. The filtrate was further subjected to ferric chloride test: $1 \mathrm{ml}$ of the filtrate was diluted with distilled water and added 2 drops of ferric chloride. A greenish to black colour indicates the presence of tannins.

Test for Flavonoid (Alkaline reagent test): $2 \mathrm{ml}$ of $2.0 \% \mathrm{NaOH}$ mixture was mixed with aqueous plant crude extract; concentrated yellow colour was produced, which become colourless when added 2 drops of dilute acid to mixture. This result showed the presence of flavonoid.

Test for phenol: $5 \mathrm{ml}$ of $90 \%$ ethanol was added to 2 $\mathrm{ml}$ of the extract, then a drop of freshly prepared $10 \%$ ferric chloride. The formation of of a darkish blue colour indicates a positive result.

Test for terpenoid (salkowski tests): To $5 \mathrm{ml}$ of the sample was added $2 \mathrm{ml}$ of chloroform, then $3 \mathrm{ml}$ of sulphuric acid. A reddish brown ring at the interface indicated a positive test.

GC-MS Analysis: $2 \mathrm{ul}$ of the sample extract was injected into the GC column for analysis. The GC (Agilent 6890N) and MS (5975B MSD) is equipped with DB-5ms capillary column $(30 \mathrm{~m} \times 0.25 \mathrm{~mm}$; film thickness $0.25 \mu \mathrm{m})$. The initial temperature was set at $40^{\circ} \mathrm{C}$ which increased to $150^{\circ} \mathrm{C}$ at the rate of $10^{\circ} \mathrm{C} / \mathrm{min}$. The temperature was again increased to $230^{\circ} \mathrm{C}$ at the rate of $5^{\circ} \mathrm{C} / \mathrm{min}$. The process continued till the temperature reached $280^{\circ} \mathrm{C}$ at the rate of 
$20^{\circ} \mathrm{C} / \mathrm{min}$ which was held for 8 minutes. The injector port temperature remained constant at $280^{\circ} \mathrm{C}$ and detector temperature was $250^{\circ} \mathrm{C}$ then. Helium was used as the carrier gas with a flow rate of $1 \mathrm{~mL} / \mathrm{min}$. Split ratio and ionization voltage were 110:1 and 70 $\mathrm{eV}$ respectively. To identify the unknown phytochemical components present in the extract, their individual mass spectral peak value was compared with the database of National Institute of Science and Technology 2014. Then the phytochemicals were identified after comparing the unknown peak value and chromatogram from GC-MS against the known chromatogram, peak value from the NIST Library database. Subsequently, the details about their molecular formula, molecular weight, retention time and percentage content were also obtained.

\section{RESULTS AND DISCUSSIONS}

The physicochemical characteristics of the chloroform extract of Icacinatri chantha tuber is presented in table 1. While the GC-MS Chromatogram of the chloroform extract of the tuber peel of Icacinatric hantha oliv is shown in figure 2 and the signal peaks of the identified compounds are presented in table 2. Identification of the peaks: Nine peaks for bioactive compounds were identified in the chloroform extract of the tuber peels of Icacinatrichanthaoliv by GC-MS. The peak 1 is presented infigure 1 . The compound identified in peak 1 is 3,3-dimethyl hexan-2-one with a formula $\mathrm{C}_{8} \mathrm{H}_{16} \mathrm{O}$ and molecular weight 128 . The R-time is 1.441 and total abundance of $23.299 \%$. The chemical structure is shown in figure 1.

Table 1: Phytochemical screening results from the Chloroform crude extract

\begin{tabular}{|c|c|}
\hline Compound & Observation \\
\hline Alkaloids & + \\
\hline Steroids & + \\
\hline Glycosides & + \\
\hline Saponins & + \\
\hline Tannins & + \\
\hline Flavonoids & + \\
\hline Phenol & + \\
\hline Terpenoids & + \\
\hline
\end{tabular}

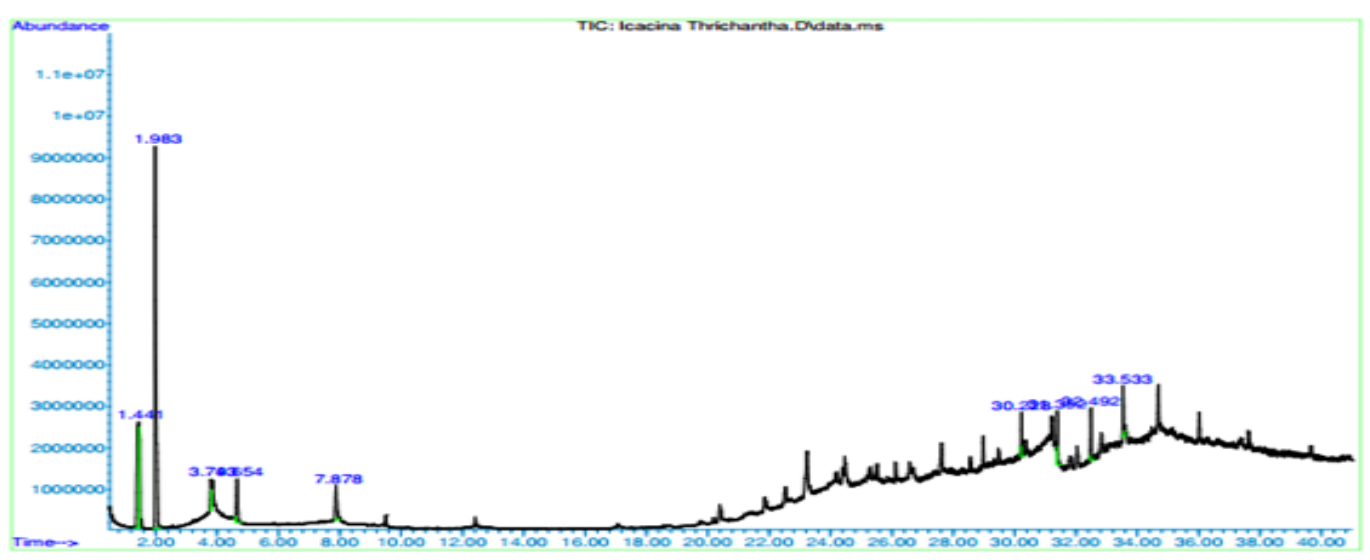

Fig 2: GC-MS Chromatogram of the chloroform extract of the tuber peel of Icacinatric hanthaoliv

\begin{tabular}{llllllllll}
\multicolumn{8}{c}{ Table 2: Signal peaks of the identified compound } \\
\hline $\begin{array}{l}\text { Peak } \\
\#\end{array}$ & R.T. & First & Max & Last & PK & Peak & Corr. area & Corr.\% & $\%$ of total \\
min & scan & scan & scan & TY & height & & max & \\
\hline 1 & 1.441 & 147 & 164 & 167 & rBV4 & 2556602 & 12207325 & $53.87 \%$ & $23.299 \%$ \\
2 & 1.983 & 248 & 257 & 281 & rBV & 9216694 & 22662592 & $100.00 \%$ & $43.254 \%$ \\
3 & 3.793 & 562 & 568 & 573 & rBV4 & 751879 & 1798518 & $7.94 \%$ & $3.433 \%$ \\
4 & 4.654 & 708 & 716 & 733 & rVB3 & 1051659 & 3271549 & $14.44 \%$ & $6.244 \%$ \\
5 & 7.878 & 1261 & 1270 & 1289 & rBV2 & 829643 & 3099188 & $13.68 \%$ & $5.915 \%$ \\
6 & 30.228 & 5106 & 5110 & 5118 & rVB2 & 1063790 & 1764013 & $7.68 \%$ & $3.367 \%$ \\
7 & 31.392 & 5307 & 5310 & 5322 & rVB4 & 1310170 & 2579709 & $11.38 \%$ & $4.924 \%$ \\
8 & 32.492 & 5494 & 5499 & 5511 & rVB2 & 1259369 & 2631987 & $11.61 \%$ & $5.023 \%$ \\
9 & 33.533 & 5674 & 5678 & 5686 & rBV5 & 1218883 & 2379027 & $10.50 \%$ & $4.541 \%$ \\
\hline \multicolumn{70}{c}{ Sum of corrected areas: 52393908} & &
\end{tabular}

The peak 2 is presented in figure 2. The compound identified in peak 2 is Undecane with a formula $\mathrm{C}_{11} \mathrm{H}_{24}$ and molecular weight 156 . The R-time is 1.983 and total abundance of $43.254 \%$. The chemical structure is shown in figure 2 . The peak 3 is presented in figure 3. The compound identified in peak is Hexadecanoic acid, 1, 1-dimethyl-1-2-ethanedyl ester with a formula $\mathrm{C}_{36} \mathrm{H}_{70} \mathrm{O}_{4}$ and molecular weight 566 . The R-time is 3.793 and total abundance of $3.793 \%$. The chemical structure is shown in figure 3 . The peak 4 is presented in figure 4. The compound identified in peak is Dodecanoic acid, ethyl ester with a formula $\mathrm{C}_{14} \mathrm{H}_{28} \mathrm{O}_{2}$ 
and molecular weight 228 . The R-time is 4.654 and total abundance of $6.244 \%$. The chemical structure is shown in figure 4.

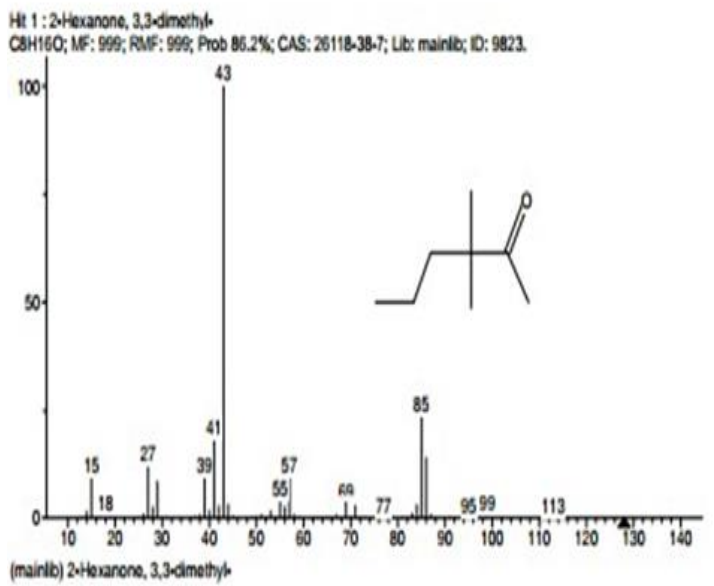

Fig.1: Bioactive compound identified in the chloroform extract of the tuber peels of Icacinatric hanthaoliv by GC-MS in peak 1

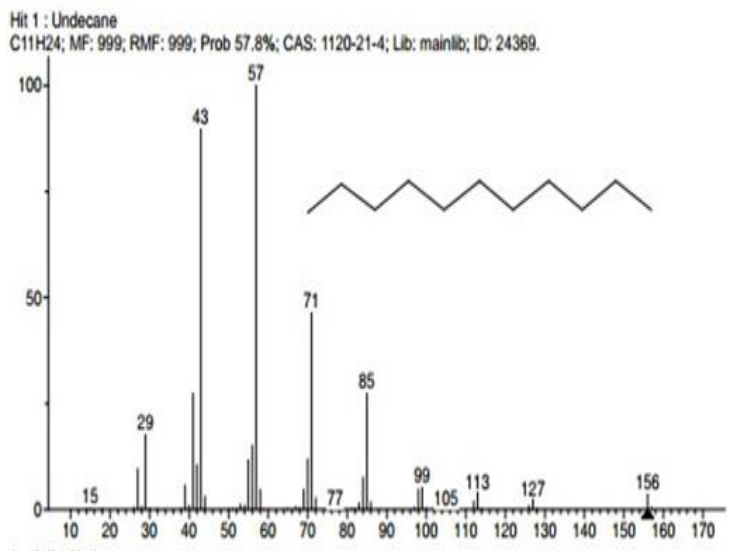
(mainlib) Undecane

Fig.2: Bioactive compound identified in the chloroform extract of the tuber peels of Icacinatric hanthaoliv by GC-MS in peak 2

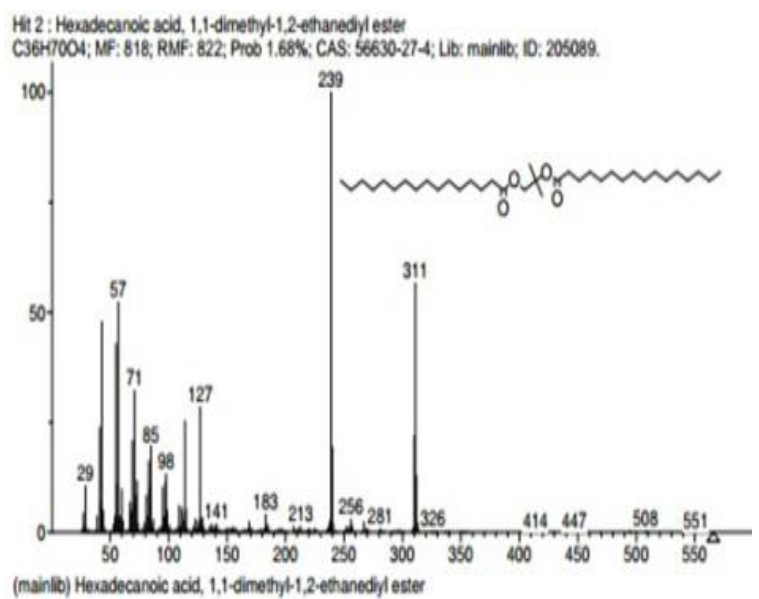

Fig.3: Bioactive compound identified in the chloroform extract of the tuber peels of Icacinatric hanthaoliv by GC-MS in peak 3

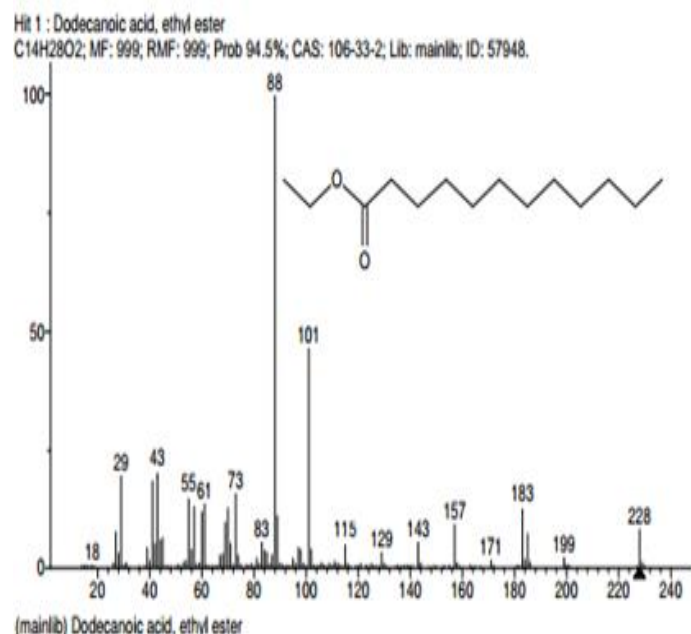

Fig.4: Bioactive compound identified in the chloroform extract of the tuber peels of Icacinatric hanthaoliv by GC-MS in peak 4

The peak 5 is presented in figure 5. The compound identified in peak is 9-Octadecynoic acid with a formula $\mathrm{C}_{18} \mathrm{H}_{32} \mathrm{O}_{2}$ and molecular weight 280 . The $\mathrm{R}$ time is 7.878 and total abundance of $5.915 \%$. The chemical structure is shown in figure 5 . The peak 6 is presented in figure 6 . The compound identified in peak is 9,12-Octadecadienoic acid, methyl ester with a formula $\mathrm{C}_{19} \mathrm{H}_{34} \mathrm{O}_{2}$ and molecular weight 294 . The $\mathrm{R}$ time is 30.228 and total abundance of $3.367 \%$. The chemical structure is shown in figure 6 . The peak 7 is presented in figure 7 . The compound identified in peak is Oleic acid with a formula and molecular weight 282. The R-time is 31.392 and total abundance of $4.924 \%$. The chemical structure is shown in figure 7.

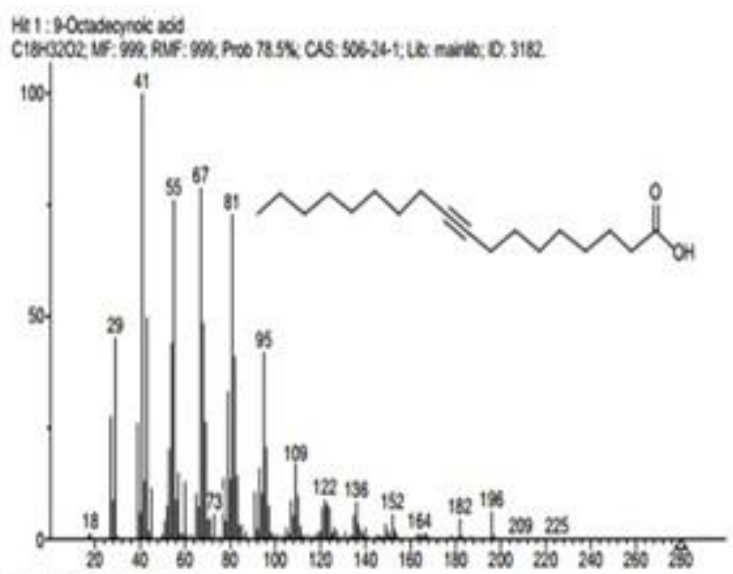

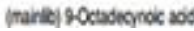

Fig.5: Bioactive compound identified in the chloroform extract of the tuber peels of Icacinatrichanthaoliv by GC-MS in peak 5 


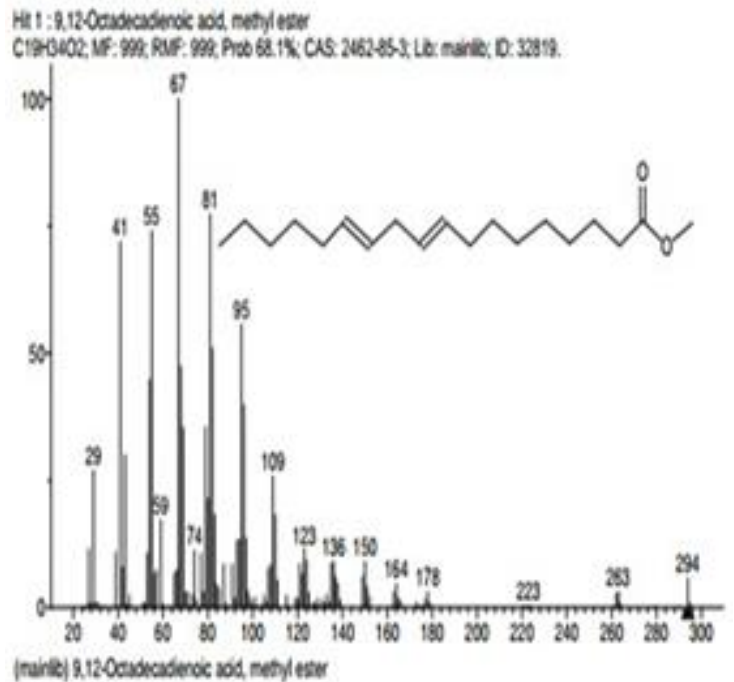

Fig.6: Bioactive compound identified in the chloroform extract of the tuber peels of Icacinatric hanthaoliv by GC-MS in peak 6

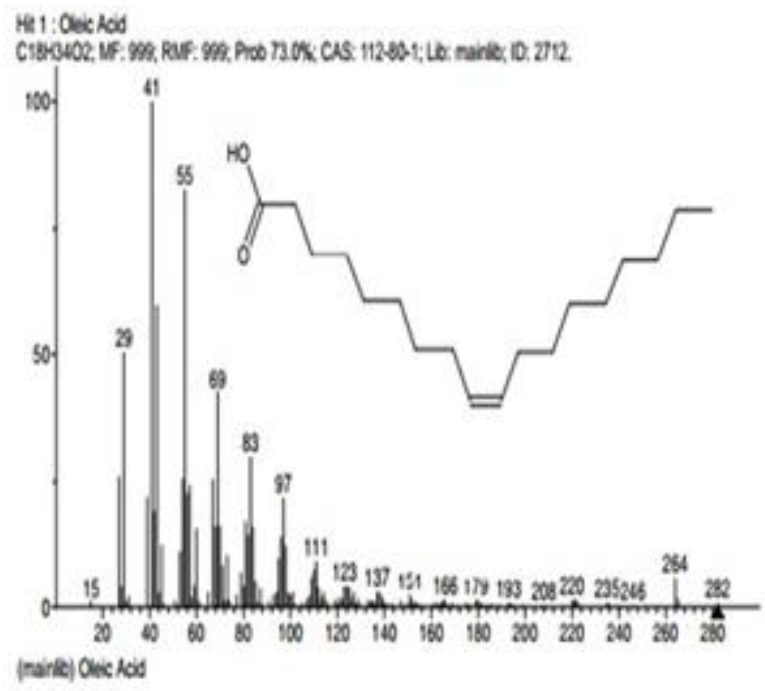

Fig.7: Bioactive compound identified in the chloroform extract of the tuber peels of Icacina trichanthaoliv by GC-MS in peak 7

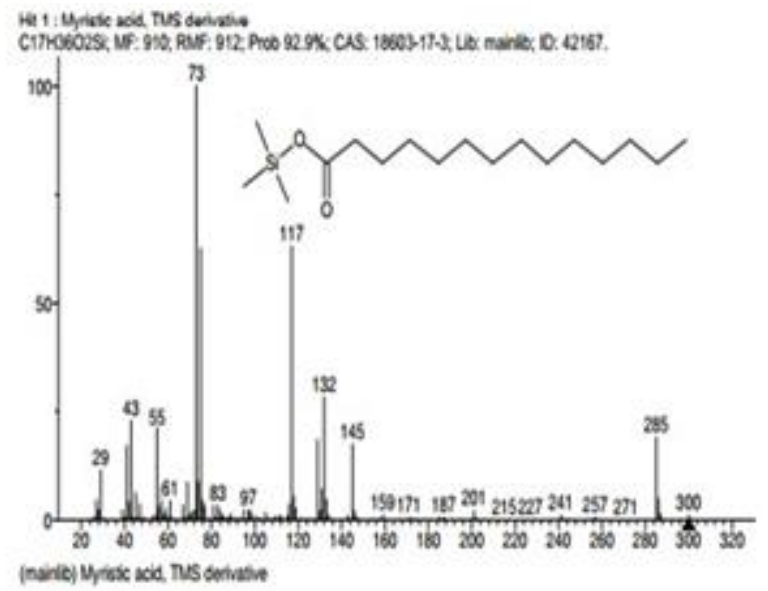

Fig.8: Bioactive compound identified in the chloroform extract of the tuber peels of Icacinatric hanthaoliv by GC-MS in peak 8

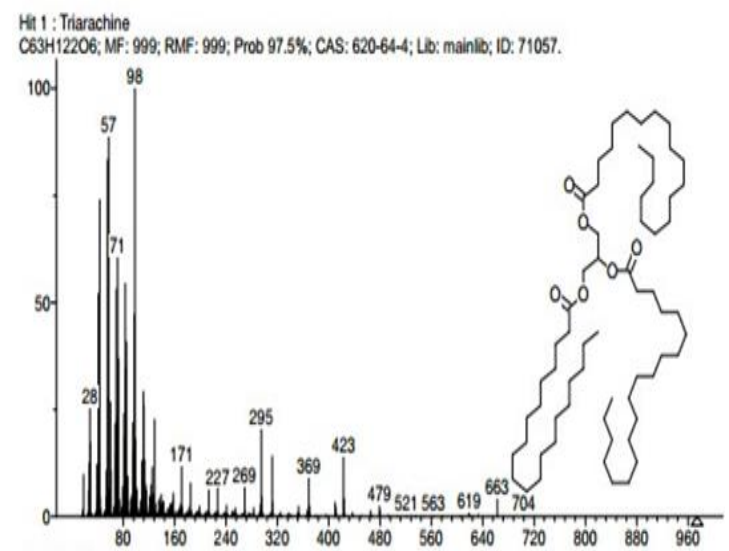

(mainlib) Triarachine

Fig.9: Bioactive compound identified in the chloroform extract of the tuber peels of Icacinatric hanthaoliv by GC-MS in peak 9Nine compounds were found in the chloroform extract of the peel of icacinatric hantha tuber peel

The peak 8 is presented in figure 8 . The compound identified in peak is Myristic acid, TMS derivative with a formula $\mathrm{C}_{17} \mathrm{H}_{36} \mathrm{O}_{2} \mathrm{Si}$ and molecular weight 300 The R-time is 32.492 and total abundance of $5.023 \%$. The chemical structure is shown in figure 8 . The peak 9 is presented in figure 9 . The compound identified in peak is Triarachine with a formula $\mathrm{C}_{63} \mathrm{H}_{122} \mathrm{O}_{6}$ and molecular weight 974 . The R-time is 33.533 and total abundance of $4.541 \%$. The chemical structure is shown in figure 9. Table 2 and Figure 2. The most prevailing compounds were Undecane $(43.254 \%), 2$ hexanone (23.299\%), Dodecanoic acid ethyl ester (6.244\%), 9-octadecynoic acid (5.915\%), Myristic acid $(5.023 \%)$, oleic acid $(4.924 \%)$ and Triarachine (4.541). These compounds are known to possess antibacterial, antiviral, antioxidant proper ties (Fay, 1987). According to Wittko Francke (1999) Undecane is the sex pheromone of ant Formica lugubris, several other ant specie contain Undecane. Undecane has also been found to be the sex pheromone of the mite Caloglyphus rodriguezi and a component of aggregation pheromones of the ant camponotus pennsylvanicus. The presence of oleic acid and myristic acids indicates that this plant part has an antimycobacterial activity (Kalim et al., 2010). The phytochemical results revealed the presence of all important phytochemicals which includes alkaloids, phenols, flavonoids, saponins, tannins, glycosides, steroids and terpenoids which comprises of six different compounds with more than $90 \%$ confirmation with the library data.

Conclusion: The use of Icacina thricantha tuber and its peel for the treatment of cough reflexes in the antibacterial, antimyco-bacterial and anti-oxidant properties. The facts that Icacina thricantha contains 
undecane, as its most prevailing compound among other bioactive compounds will make it useful in agricultural industry as a pheromone and in cosmetics industry if properly explored.

\section{REFERENCES}

Awa, EP., Ibrahim, S., Ameh, DA (2012). GC-MS analysis and antimicrobial activity of diethyl ether fraction of methanolic extract from thr stem bark of Annonasenegalensis Pers. Int .J. Phatm. Sci. Res. 3; 4213-4218.

Burkhill, HM (1985). The Useful Plants of West Tropical Africa.2nd Edition.Royal Botanic Gardens, Kew, UK. 452-453.

Burkhill, HM (1994).The Useful Plants of West

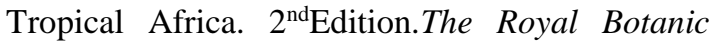
Gardens, Kew, UK., 418-419

Della-loggia, R (1999). Chloroform fraction significantly reduced also the carrageen induced paw edema in rats. Phytomedicine. 6(4): 267-272.

Edorios, E (2015). Phytochemical screening of aqueous extract of Icacinatrichantha roots and its effect on the mortality of wood termite. World Journal of Pharmaceutical Research, 4, 213-224

Holldobler., Wilson (1990). The Ants. Harvard University Press ISBN 0674-04075-9,.287

Ezeigbo, II (2010) Autidiabetic potential of methanolic leaf extracts of Icacina trichantha in alloxan-induced diabetic mice. International Journal of Diabetes in Developing Countries, 30; 150-152

Shagal, MH. ,Mukhtar, H., Akinterinwa, A.,Ndahi, JA (2014) Phytochemical investigation of methanolic extract of Icacinatrichantha tuber. International Journal of current Microbiology and Applied Sciences, 3, 907-911.

Ajibensin, KK.., Ekpo, BA, Bala, DN., Essien, EE., Adesanya, SA (2008). Ethnobotanical Survey of AkwaIbom State of Nigeria.JEthnopharmacol, $115,387-408$

Ubom, RM (2010) Ethnobotany and biodiversity conservation in the Niger Delta, Nigeria, Int. J. Bot, 6, 310-322

Fay, JM (1987) IcacinaOliviformis; a close look at an underexploited food plant. I. Overview and ethnobotany.Econoic Botany, 41,512-522.

Kalim, MD., Bhattacharyya, D., Banerjee A., Chattopadhyay, S (2010). Oxidative DNA damage preventive activity and antioxidant potential of plants used in Unani system of medicine. BMC Complementary and Alternative medicine, 10: 0111.

Wittko F; Stefan S (1999) Miscellaneous natural products including marine natural, pheromones, plant hormones, and aspects of ecology. Comprehensive natural products chemistry, 8,04.4.12 